Lyra Valera Veloro, MD ${ }^{1}$

Michael Alexius Adea Sarte, MD ${ }^{1,2}$

Samantha Soriano Castañeda, MD ${ }^{1,3,4}$

1 Department of Otolaryngology Head and Neck Surgery The Medical City

${ }^{2}$ The Center for Snoring and Sleep Disorders The Medical City

${ }^{3}$ Department of Otolaryngology Head and Neck Surgery Rizal Medical Center

${ }^{4}$ Department of Otolaryngology Head and Neck Surgery Jose Reyes Memorial Medical Center
Correspondence: Lyra Valera Veloro, MD Department of Otolaryngology Head and Neck Surgery PO218 $2^{\text {nd }}$ floor, Hospital Podium

The Medical City

Ortigas Avenue, Pasig City 1600

Philippines

Phone: (632) 6356789 loc 6250

Telefax: (632) 6873349

Email: lyraveloro@yahoo.com

Reprints will not be available from the author.

No funding support was received for this study. The authors signed a disclosure that they have no proprietary or financial interest with any organization that may have a direct interest in the subject matter of this manuscript, or in any product used or cited in this article.

Presented at the $22^{\text {nd }}$ Annual Interdepartmental Research Contest (1st Place, Descriptive Studies Category), The Medical City, Pasig; December 7, 2006

Analytical Research Contest (1st Place), Philippine Society of Otolaryngology - Head and Neck Surgery $51^{\text {st }}$ Annual Convention, Sofitel Philippine Plaza Manila, Pasay City, Philippines, December 1, 2007.

\title{
Collar Size as Predictor of Obstructive Sleep Apnea
}

\begin{abstract} particularly collar size and Body Mass Index (BMI), and polysomnographic parameters in male (OSA).

\section{Methods:}

Design: Cross-sectional study

Setting: Academic tertiary private hospital

Subjects: Charts of 149 adult male patients referred for polysomnography between July 1,2005 and June 30,2006 were reviewed. Height, weight and external neck circumference measurements were obtained. The data from polysomnography results were noted and correlated with the physical measurements.
\end{abstract}

Objective: This study focuses on evaluating the relationship between physical findings, patients seen at a Sleep Disorders Laboratory, suspected to have Obstructive Sleep Apnea

Results: The mean collar size for the OSA group was $42.03 \mathrm{~cm}$ with a mean BMI of 29.14 while the mean collar size for the normal group was $39.05 \mathrm{~cm}$ with a mean BMI of 25.36. A significant difference was noted in both the collar size and body mass index (BMI) between the OSA group and the normal group $(p<0.005)$. Results showed a significant correlation between collar size and BMI. Collar size and BMI measurements were also correlated with increasing severity of sleep apnea in the OSA group. The $\geq 40 \mathrm{~cm}$ collar size among male adults with symptoms of OSA was $80 \%$ sensitive and $67 \%$ specific with a positive predictive value of $94 \%$ in predicting true OSA.

Conclusion: This study suggests that the external neck circumference and the degree of obesity determined through BMI measurement may be important predictors of sleep apnea in adult Filipino males suspected to have OSA. Given the high probability of having true OSA in symptomatic male adults with a collar size $\geq 40 \mathrm{~cm}$, outright definitive management may be opted for in these patients, while those with a collar size $<40 \mathrm{~cm}$ may need to undergo further confirmatory tests.

Key words: obstructive sleep apnea, external neck circumference, collar size, body mass index, polysomnography, obesity

Because of the significantly increased risk of morbidity and mortality, patients with obstructive sleep apnea (OSA) must be diagnosed and treated vigorously. Clinical evaluations following previous studies consider tonsil size, Mallampati score, Body Mass Index (BMI), neck circumference and lateral craniofacial assessment. Of these, the BMI has been found to be the most important physical parameter for the prediction of OSA.

Philipp J Otolaryngol Head Neck Surg 2008; 23 (2): 14-16

(c) Philippine Society of Otolaryngology - Head and Neck Surgery, Inc 
For a BMI higher than $28 \mathrm{~kg} / \mathrm{m}^{2}$ in males and $27 \mathrm{~kg} / \mathrm{m}^{2}$ in females, the incidence of OSA has been reported at approximately $30 \%{ }^{1}$ Even a $5 \%$ to $10 \%$ decrease in body weight in some obese individuals with OSA can lead to substantial clinical and objective improvement in sleepdisordered breathing. ${ }^{2}$ Although a positive correlation has been found between $\mathrm{BMI}$ and severity of OSA, BMI does not necessarily predict the presence of OSA.'

Although neck circumference correlated significantly with BMI in both men and women, the neck circumference measured independently from the $\mathrm{BMI}$ is thought to be a very important parameter for the diagnosis of OSA. OSA is reported to be present in $30 \%$ of patients with a neck circumference of $43 \mathrm{~cm}$ in males or $38 \mathrm{~cm}$ in females in one study. ${ }^{3}$ Others, on the other hand, reported no correlation between increasing neck circumference and severity of OSA. Currently, Polysomnography (PSG) is regarded as the most valuable standard and definitive method for establishing the diagnosis of OSA. PSG continues to be the gold standard for the diagnosis of OSA. ${ }^{4}$ Unfortunately, the role of physical findings in the diagnosis of sleep apnea is unclear.

This study focuses on evaluating the correlation between physical findings, particularly collar size and $\mathrm{BMI}$, and polysomnographic parameters in patients attending our clinic suspected to have OSA.

Design: Cross-sectional study

\section{METHODS}

Setting: Academic tertiary private hospital

Subjects: All charts of adult Filipino male patients referred for polysomnography (PSG) to the Center for Snoring and Sleep Disorders between July 1, 2005 and June 30, 2006 were retrospectively reviewed. Included were males 19 years old and above with no craniofacial or neurologic abnormalities and no previous operations in the head and neck region, suspected to have OSA based on history (loud snoring, cessation of breathing during sleep, frequent arousals at night, chronic daytime sleepiness or fatigue) and physical examination findings (tonsil size, Mallampati scores). Height in meters, weight in kilograms and external neck circumference in centimeters (or collar size) taken prior to PSG were obtained from patient's charts as well as records of co-morbidities for sleep apnea: hypertension, stroke, heart disease or adult-onset diabetes. The BMI was obtained by weight in $\mathrm{kg}$ divided by the square of height in meters.

Outcome measure: The results of the PSG were noted and correlated with the physical measurements.

Data and Statistical Analysis: Based on the objectives, statistical analyses included Spearman rho correlation for categorical data and chi-square test for association significance.

\section{RESULTS}

One hundred forty nine (149) male patients fulfilled the inclusion criteria. Of these, 128 were diagnosed with obstructive sleep apnea (OSA) by polysomnography while 21 had normal results. The mean age was 45.23 years with a standard deviation of 10.72 . The mean collar size for all patients was $41.61 \mathrm{~cm}$ and the mean BMI was 28.61 .
There was no significant difference in age between the group with OSA ( $n=128)$ and the normal group $(n=21)$. The mean collar size for the OSA group was $42.03 \mathrm{~cm}$ with a mean BMI of 29.14 while the mean collar size for the normal group was $39.05 \mathrm{~cm}$ with a mean BMI of 25.36. A significant difference was noted for both the collar size and body mass index (BMI) between the OSA group and the normal group $(p<0.005)$. (Table 1)

In the OSA group, 16 (12.5\%) were in the mild category (RDI of 5 to $<10$ ) with a mean collar size of $38.4 \mathrm{~cm}$ and a mean BMI of 25.96; fortyone $(32 \%)$ were in the moderate group (RDI of 10 to $<30$ ) with a mean collar size of $41.58 \mathrm{~cm}$ and mean BMI of 29.39; seventy-one (55.5\%) were classified as severe (RDI of $>/=30$ ) with a mean collar size of 43.09 $\mathrm{cm}$ and a mean BMI of 29.7 .

The severity of OSA was subsequently classified into normal, mild, and moderate-severe categories as multiple comparison tests showed no significant difference in collar size between those with moderate OSA and those with severe OSA (Table 2). The collar size increased progressively with increasing severity of sleep apnea.

Likewise, the body mass index (BMI) was related to the severity of sleep apnea and different among the groups mentioned $(p<0.005)$. (Table 3)

\section{Search for a cut-off point}

Collar sizes for the normal group ranged from $33.02 \mathrm{~cm}$ to $48 \mathrm{~cm}$. Collar sizes for the OSA group ranged from $30.37 \mathrm{~cm}$ to $48.26 \mathrm{~cm}$. Twenty-three percent (23\%) of the total patients and $24 \%$ of patients diagnosed with OSA had a 40 -centimeter collar size. Only $2-5 \%$ of subjects had other collar sizes. On account of the considerable number of the study population clustering in the 40-centimeter collar size, it was selected as the cut-off point and was tested for its predictive value.

Of the study population, a total of 109 subjects had a collar size $\geq$ $40 \mathrm{~cm}$, while 40 subjects had a collar size of $<40 \mathrm{~cm}$. For purposes of screening patients with OSA as a positive test, the $\geq 40 \mathrm{~cm}$ collar size had a sensitivity, specificity and positive predictive value of $80 \%, 67 \%$ and $94 \%$, respectively. (Table 4)

\section{DISCUSSION}

OSA is currently thought to be caused by a dynamic process with contributions from structural upper airway narrowing and abnormal upper airway neuromotor tone. ${ }^{5}$ Subjective complaints have not yielded enough sensitivity and specificity, prompting attempts to clinically evaluate physical parameters and their relevance to the diagnosis of OSA. ${ }^{1}$

External neck circumference, particularly collar size, has been assessed in several studies with conflicting outcomes. ${ }^{1}$ Our results may suggest that collar size may be an independent parameter for determining OSA. This correlation between sleep apnea and neck circumference may reflect "mass loading," with the static pharyngeal size modulated by dynamic loading of the airway due to the weight of fatty neck tissue contributing to the pathogenesis of OSA. ${ }^{6}$

Statistical analyses suggested a significant difference between the mild and moderate OSA groups, but no significant difference between moderate and severe stages. This may support a classification 
Table 1. Demographic and anthropometric parameters for normal and OSA subjects

\begin{tabular}{|c|cc|cc|cc|}
\hline \multirow{2}{*}{$\begin{array}{c}\text { Total subjects } \\
\text { N=149 }\end{array}$} & \multicolumn{2}{|c|}{$\begin{array}{c}\text { w/0SA } \\
\mathbf{n = 1 2 8}\end{array}$} & \multicolumn{2}{|c|}{$\begin{array}{c}\text { Normal } \\
\mathbf{n = 2 1}\end{array}$} & \multicolumn{2}{|c|}{} \\
\cline { 2 - 5 } & Mean & SD & Mean & SD & Mean Diff & P-value \\
AGE (yrs) & 45.49 & 10.35 & 43.67 & 12.96 & 1.83 & 0.545 \\
COLLAR (cm) & 42.03 & 3.53 & 39.06 & 3.17 & 2.98 & $0.001^{*}$ \\
BMI & 29.14 & 4.84 & 25.36 & 5.19 & 3.78 & $0.004^{*}$ \\
\hline
\end{tabular}

Table 2. Severity of OSA classified into normal, mild, and moderate-severe

\begin{tabular}{|c|c|c|c|c|c|c|c|c|}
\hline & \multirow{2}{*}{\multicolumn{2}{|c|}{$\begin{array}{l}w / 0 S A \\
N=128\end{array}$}} & \multirow{2}{*}{\multicolumn{2}{|c|}{$\begin{array}{l}\text { MILD } \\
\mathrm{n}=16\end{array}$}} & \multirow{2}{*}{\multicolumn{2}{|c|}{\begin{tabular}{|c|} 
MODERATE \\
$n=41$
\end{tabular}}} & \multirow{2}{*}{$\begin{array}{c}\text { SEVERE } \\
\mathrm{n}=41\end{array}$} & \multirow{3}{*}{$\begin{array}{c}\text { Multiple } \\
\text { Comparison Test }\end{array}$} \\
\hline & & & & & & & & \\
\hline & Mean & SD & Mean & SD & Mean & SD & Mean SD & \\
\hline AGE & 45.5 & 10.3 & 45.6 & 11.3 & 45.0 & 10.58 & $\begin{array}{ll}45.8 & 10.14\end{array}$ & \multirow{3}{*}{$\begin{array}{c}\text { No diff accoss age } \\
\text { mild }< \\
\text { Moderate \& Severe } \\
\text { Mild }< \\
\text { Moderate \& Severe }\end{array}$} \\
\hline COLLAR & 42.0 & 3.53 & 38.5 & 3.46 & 41.6 & 3.28 & $43.1 \quad 3.13$ & \\
\hline BMI & 29.1 & 4.84 & 26.0 & 4.23 & 29.4 & 6.05 & $29.7 \quad 3.88$ & \\
\hline
\end{tabular}

Table 3. Collar size and BMI related to severity of OSA

\begin{tabular}{|c|cc|cc|cc|cc|c|}
\multirow{2}{*}{} & \multicolumn{2}{|c|}{ w/OSA } & \multicolumn{2}{c|}{ MILD } & \multicolumn{2}{c|}{ MODERATE } & \multicolumn{2}{c|}{ SEVERE } & \multirow{2}{*}{} \\
\cline { 2 - 7 } AGE (yrs) & Mean & SD & Mean & SD & Mean & SD & Mean & SD & P-value \\
COLLAR (cm) & 10.35 & 45.56 & 11.30 & 45.05 & 10.58 & 45.73 & 10.14 & 0.945 \\
BMI & 42.03 & 3.53 & 38.50 & 3.46 & 41.58 & 3.28 & 43.09 & 3.13 & $0.000^{*}$ \\
\hline & 29.14 & 4.84 & 25.97 & 4.23 & 29.39 & 6.05 & 29.72 & 3.88 & $0.017^{*}$ \\
\hline
\end{tabular}

Table 4. Sensitivity-specificity analysis of 40-centimeter cut-off point in screening patients for OSA

\begin{tabular}{|l|c|c|}
\hline Positive Predictive Value & $94 \%$ & 102 out of 109 \\
\hline Negative Predictive Value & $35 \%$ & 14 out of 40 \\
\hline False Positive \% & $33 \%$ & 7 out of 21 \\
\hline False Negative \% & $20 \%$ & 26 out of 128 \\
\hline Sensitivity & $80 \%$ & 102 out of 128 \\
\hline Specificity & $67 \%$ & 14 out of 21 \\
\hline
\end{tabular}

*Significant Difference consisting of a normal group, a mild OSA group and a moderate-severe OSA group. Collar size and BMI were significantly different among these groups and increased progressively with increasing severity of sleep apnea. The importance of this classification may guide the treatment plan within each category and the management differences between each category.

Among Caucasians, OSA is reported to be present in $30 \%$ of patients with a neck circumference of $43 \mathrm{~cm}$ in males. ${ }^{3}$ Data in the Philippine setting is lacking with regards a good collar size cut off point for predicting OSA prompting utilization of results from this study as preliminary data to establish associations between collar size and diagnosis of OSA locally. Forty centimeters was suggested as a cut-off point for predicting OSA in Filipinos owing to the major percentage of the study population as well as subjects diagnosed with OSA falling into this measurement. Validation studies in the future may require ROC (receiver operating characteristics) analysis for identification of cut-off values with a balanced negative and positive prediction for OSA. Results have shown that $\mathrm{a} \geq 40 \mathrm{~cm}$ collar size presents with $94 \%$ probability of OSA in adult Filipino male subjects referred for polysomnography. Hence, given the high probability of true OSA in symptomatic male adults with a collar size $\geq 40 \mathrm{~cm}$, outright definitive management may be opted for in these patients, while those with a collar size $<40 \mathrm{~cm}$ may need to undergo further confirmatory tests. Standard criterion studies may validate these results.

\section{ACKNOWLEDGEMENTS}

The authors would like to thank Ms. Lilian Talag and the rest of the staff of the Center for Snoring and Sleep Disorders for technical assistance and data collection, Ms. Diane Locayon for statistical analysis and Drs. Daniel Alonzo (department chair) and Peter Jarin (training officer) for their unwavering support.

\section{REFERENCES}

1. Erdamar B, Suoglu Y, Cuhadaroglu C, Katircioglu S, Guven M. Evaluation of clinical parameters in patients with obstructive sleep apnea and possible correlation with the severity of the disease Eur Arch of Otol 2001; 258: 492-495.

2. Guce A. Obstructive sleep apnea syndrome: a deadly slumber. JMPA Vol. 74 Nos. 1-4 (July 1998June 1999); Vol. 75 Nos. 1-4 (July 1999-June 2000).

3. Guilleminault C, Stoohs R., Kim YD. Upper airway sleep-disordered breathing women. Ann Int Med. 1995; 122: 493-501.

4. Gupta V, Reiter E. Current practices in obstructive sleep apnea and snoring. Am J Otolaryngol. 2004 Jan-Feb; 25(1): 18-25.

5. Greefield M. Obstructive sleep apnea syndrome due to adenotonsillar hypertrophy in infants. Int J Ped Otolaryngol. 2003; 67(10): 1055-1060.

6. Katz I, Stradling J, Slutsky AS, Zamel N and Hoffstein V. Do patients with obstructive sleep apnea have thick necks? Am Rev Respir Dis 1990;141:1228-1231. 